NASA/TM-2002-211475

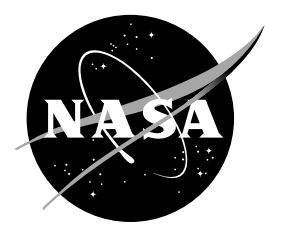

\title{
Calculation and Correlation of the Unsteady Flowfield in a High Pressure Turbine
}

\author{
Milind A. Bakhle \\ University of Toledo, Toledo, Ohio \\ Jong S. Liu and Josef Panovsky \\ Honeywell Engines, Systems, \& Services, Pheonix, Arizona \\ Theo G. Keith, Jr. \\ University of Toledo, Toledo, Ohio \\ Oral Mehmed \\ Glenn Research Center, Cleveland, Ohio
}


Since its founding, NASA has been dedicated to the advancement of aeronautics and space science. The NASA Scientific and Technical Information (STI) Program Office plays a key part in helping NASA maintain this important role.

The NASA STI Program Office is operated by Langley Research Center, the Lead Center for NASA's scientific and technical information. The NASA STI Program Office provides access to the NASA STI Database, the largest collection of aeronautical and space science STI in the world. The Program Office is also NASA's institutional mechanism for disseminating the results of its research and development activities. These results are published by NASA in the NASA STI Report Series, which includes the following report types:

- $\quad$ TECHNICAL PUBLICATION. Reports of completed research or a major significant phase of research that present the results of NASA programs and include extensive data or theoretical analysis. Includes compilations of significant scientific and technical data and information deemed to be of continuing reference value. NASA's counterpart of peerreviewed formal professional papers but has less stringent limitations on manuscript length and extent of graphic presentations.

- TECHNICAL MEMORANDUM. Scientific and technical findings that are preliminary or of specialized interest, e.g., quick release reports, working papers, and bibliographies that contain minimal annotation. Does not contain extensive analysis.

- CONTRACTOR REPORT. Scientific and technical findings by NASA-sponsored contractors and grantees.
- CONFERENCE PUBLICATION. Collected papers from scientific and technical conferences, symposia, seminars, or other meetings sponsored or cosponsored by NASA.

- SPECIAL PUBLICATION. Scientific, technical, or historical information from NASA programs, projects, and missions, often concerned with subjects having substantial public interest.

- TECHNICAL TRANSLATION. Englishlanguage translations of foreign scientific and technical material pertinent to NASA's mission.

Specialized services that complement the STI Program Office's diverse offerings include creating custom thesauri, building customized data bases, organizing and publishing research results ... even providing videos.

For more information about the NASA STI Program Office, see the following:

- Access the NASA STI Program Home Page at http://www.sti.nasa.gov

- E-mail your question via the Internet to help@sti.nasa.gov

- Fax your question to the NASA Access Help Desk at 301-621-0134

- Telephone the NASA Access Help Desk at 301-621-0390

- Write to:

NASA Access Help Desk

NASA Center for AeroSpace Information 7121 Standard Drive

Hanover, MD 21076 
NASA/TM-2002-211475

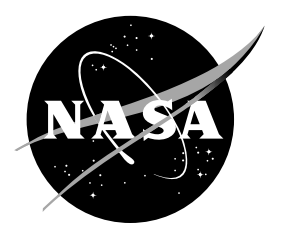

\title{
Calculation and Correlation of the Unsteady Flowfield in a High Pressure Turbine
}

\author{
Milind A. Bakhle \\ University of Toledo, Toledo, Ohio \\ Jong S. Liu and Josef Panovsky \\ Honeywell Engines, Systems, \& Services, Pheonix, Arizona \\ Theo G. Keith, Jr. \\ University of Toledo, Toledo, Ohio \\ Oral Mehmed \\ Glenn Research Center, Cleveland, Ohio
}

Prepared for the

Turbo Expo 2002

sponsored by the American Society of Mechanical Engineers

and the International Gas Turbine Institute

Amsterdam, The Netherlands, June 3-6, 2002

National Aeronautics and

Space Administration

Glenn Research Center 


\section{Acknowledgments}

This work was funded by the NASA Glenn Research Center's Office of Chief Scientist; the support is gratefully acknowledged. The turbine test data was obtained under a GUIde Consortium contract. The authors would like to thank the GUIde consortium for allowing the data to be used for code validation. The authors would like to thank

Mr. Jason Kielb of Rolls-Royce for numerous consultations regarding the data. Also, the authors would like to thank Dr. Jen-Ping Chen of Mississippi State University for providing assistance with the TURBO code.

This report is a preprint of a paper intended for presentation at a conference. Because of changes that may be made before formal publication, this preprint is made available with the understanding that it will not be cited or reproduced without the permission of the author.

Available from

NASA Center for Aerospace Information 7121 Standard Drive

Hanover, MD 21076
National Technical Information Service 5285 Port Royal Road Springfield, VA 22100 


\title{
CALCULATION AND CORRELATION OF THE UNSTEADY FLOWFIELD IN A HIGH PRESSURE TURBINE
}

\author{
Milind A. Bakhle \\ University of Toledo \\ Toledo, Ohio \\ Jong S. Liu and Josef Panovsky \\ Honeywell Engines, Systems, \& Services \\ Pheonix, Arizona \\ Theo G. Keith, Jr. \\ University of Toledo \\ Toledo, Ohio \\ Oral Mehmed \\ National Aeronautics and Space Administration \\ Glenn Research Center \\ Cleveland, Ohio
}

\begin{abstract}
Forced vibrations in turbomachinery components can cause blades to crack or fail due to high-cycle fatigue. Such forced response problems will become more pronounced in newer engines with higher pressure ratios and smaller axial gap between blade rows. An accurate numerical prediction of the unsteady aerodynamics phenomena that cause resonant forced vibrations is increasingly important to designers. Validation of the computational fluid dynamics (CFD) codes used to model the unsteady aerodynamic excitations is necessary before these codes can be used with confidence. Recently published benchmark data, including unsteady pressures and vibratory strains, for a high-pressure turbine stage makes such code validation possible. In the present work, a three dimensional, unsteady, multi blade-row, Reynolds-Averaged Navier Stokes code is applied to a turbine stage that was recently tested in a short duration test facility. Two configurations with three operating conditions corresponding to modes 2,3 , and 4 crossings on the Campbell diagram are analyzed. Unsteady pressures on the rotor surface are compared with data.
\end{abstract}

\section{INTRODUCTION}

Forced vibrations in turbomachinery components can cause High Cycle Fatigue (HCF) failures in blades. Modern turbomachinery blade designs have higher pressure ratios and smaller axial gap between blade rows, which can cause an increase in forced response problems. These problems are typically not discovered until late in the engine development stage. This can lead to increased development time and cost, increased maintenance cost, and reduced operational readiness. Accurate numerical prediction of the unsteady aerodynamics phenomena that cause resonant forced vibrations can lead to an improved understanding of the problem and offer potential approaches to reduce or eliminate specific forced response problems.

Although the Campbell diagram can identify regions of potential problems, the actual magnitude of the aerodynamic excitation can only be obtained from experimental measurements or unsteady aerodynamic modeling. Without knowing the level of excitation, it is impossible to determine whether a particular crossing will result in problems. With recent advances in CFD modeling techniques and increased availability of computational resources, it is now possible to model a turbine stage in considerable detail. Such modeling, which includes three dimensional and viscous effects, can provide details of the unsteady flow phenomena and yield the aerodynamic excitation to calculate the blade vibratory response. However, validation of such CFD-based models requires unsteady aerodynamic data. Recently, such data has become available for a full-scale turbine stage operating at 
engine conditions [1]. This data, acquired in a short duration test facility (shock tunnel), includes measurements of the unsteady pressure on the blade surface and the vibratory response of the blades to excitations from upstream vanes at different operating speeds. Further, this data set includes measurements at two different axial gaps between the stator and the rotor. The test article is an initial design for a highpressure turbine stage, which experienced forced response vibrations. An increase in the axial gap was required to eliminate the forced vibrations. This benchmark data is suitable for validation of unsteady aerodynamics and aeroelastic analysis codes.

In the present work, a 3D, unsteady, multi blade-row, Reynolds-Averaged Navier Stokes (RANS) code, TURBO, developed by Chen et al. [2-4] is applied to the high pressure turbine (HPT) stage for which benchmark experimental data is available. Two configurations are analyzed with different axial spacing between blade rows. Three operating conditions corresponding to modes 2,3 , and 4 resonant crossings on the Campbell diagram are analyzed. Two grids are used to evaluate the effects of spatial discretization. Unsteady blade surface pressures are Fourier transformed to time average and first harmonic components and compared with the data at $50 \%$ and $85 \%$ span, which were the locations of the pressure transducers in the experiment. In addition, plots of the flowfield are presented to view how upstream wakes interact with downstream rotor. The results presented show the effect of axial spacing on the unsteady flowfield on the downstream rotor. The paper summarizes the results of the comparison of the numerical predictions with data, and concludes with some recommendations for future work.

\section{DESCRIPTION OF EXPERIMENTAL DATA}

The detailed experimental data was published by Kielb et al. in Refs. $[1,5,6]$. The data was acquired in a short duration test facility at the Gas Turbine Lab of the Ohio State University. The test article was a high pressure turbine in which the rotor has experienced excessive vibrations due to pressure wakes from upstream stators. The on-blade instrumentation included pressure transducers and strain gages. The data was acquired at and near the resonant crossings of the second $\left(1^{\text {st }}\right.$ torsion), third (axial) and fourth ( $2^{\text {nd }}$ bending) modes with the 41 engine order excitations from upstream vanes. Measurements were obtained for two axial spacings between the stator and rotor. The surface pressure measurements were presented as plots of time-averaged and two harmonics components with axial chord location at $50 \%$ and $85 \%$ span locations.

\section{DESCRIPTION OF TURBOMACHINERY UNSTEADY FLOW CODE}

The Reynolds-averaged Navier Stokes turbomachinery code used in the present study is the TURBO code $[2-4,7,8]$. This $3 \mathrm{D}$, unsteady, multi blade-row code is a structured grid solver based on an implicit finite volume algorithm. Flux vector splitting is used to evaluate the flux Jacobians on the left hand side of the governing equations and Roe's flux difference splitting is used to form a higher-order TVD (Total Variation Diminishing) scheme to evaluate the fluxes on the right hand side. Newton sub-iterations are used at each time step to maintain higher accuracy. Symmetric Gauss-Seidel iterations are applied to the discretized equations. Viscous terms are modeled explicitly and the two-equation k-epsilon turbulence model is used for closure.

For rotor-stator interaction calculations, various approaches are possible to model the unsteady flow field. If periodic boundary conditions are used in the blade-to-blade direction, it may be necessary to include multiple blade passages in each blade row. For example, in the present work, the turbine has 41 stators and 78 rotors. Use of periodic boundary conditions would require calculations to include 41 stator passages and 78 rotor passages. Alternately, one could modify the number of stators from 41 to 39 and change the solidity accordingly so that the calculations can be done with 1 stator passage and 2 rotor passages.

The approach adopted in the present work is to model the actual geometry without modifications and to use phase-lag boundary conditions so that only one passage from each row needs to be included in the calculations. The boundary conditions are based on the direct-store method [9] and the implementation of these in the TURBO code is described in Refs. [3,4]. The history of flow variables is stored and continually updated at the interface between the two blade rows. These stored flow variables are available as interface boundary conditions for the rotor and stator blade passage, regardless of its relative location. The same technique is applied to the circumferentially periodic boundaries of both rotor and stator passages.

\section{DETAILS OF UNSTEADY FLOW COMPUTATIONS}

The computational grids used in the present calculations are smoothed H-grids. The stator and rotor passage grids were $95 \times 43 \times 37$ (axial $x$ radial $x$ circumferential) and $93 \times 43 \times 37$, respectively, with 55 points in the axial direction on each surface between leading and trailing edges. Figure $1 \mathrm{a}$ and $1 \mathrm{~b}$ show sample grids at the mid-span location in the cascade plane. Although multiple passages are shown for clarity, the calculation domain includes only one blade passage in each blade row.

The computations using the TURBO code were started from a uniform flow and converged to periodicity. Computations were performed for two values of axial spacing between stator and rotor: $32 \%$ and $46 \%$ of stator chord, referred to as the small and large gap. The rotational speed, inlet total conditions, and exit static pressure used in the TURBO calculations were the values reported in Ref. [6]. Table 1 summarizes the conditions for the 6 different runs. The run numbers listed correspond to those in Ref. [6]. 


\section{RESULTS}

Initial results presented in this section seek to demonstrate the periodicity of the unsteady solutions, and the effect of the time step, and other numerical parameters on the unsteady pressure results. These calculations were performed for the Run 1 conditions. The results presented later in this section show the comparison between the computational results and measurements at two spanwise locations for Run 1 and 11 conditions. Finally, select results are presented for Run 4 and 7 conditions. Note that surface pressures have been normalized by the inlet total pressure.

The periodicity of the flowfield was checked by monitoring the unsteady pressure at many locations. In Fig. 2, the variation of unsteady blade surface pressure at selected locations is plotted against time. The quantity plotted is the difference between instantaneous pressure and the timeaveraged pressure, scaled by the inlet total pressure. The plots are for the two spanwise locations at which measurements were obtained. The chordwise locations are near the leading edge, near the mid-chord, and near the trailing edge on both blade surfaces.

It can be seen that excellent flow periodicity is present in the vicinity of the leading edge and mid-chord. Near the trailing edge location at $50 \%$ span, small differences are seen in the surface pressure from one cycle to the next. Near the trailing edge location at $85 \%$ span, the lack of periodicity is quite noticeable. Note that this aperiodicity is restricted to a small region near the trailing edge and is not eliminated by continuing the unsteady calculations for a longer time. The dominant frequency of the unsteadiness in the trailing edge region is not the blade passing frequency, but nearly six times larger. These high frequency variations in pressure are caused by vortex shedding at the rotor trailing edge, which is clearly observed in the flow visualization plots presented later (for example, Fig. 5). The difference in periodicity between the $85 \%$ and $50 \%$ span locations is also caused by differences in the vortex shedding patterns as seen in these flow visualization plots.

\section{Effect of Numerical Parameters}

In Fig. 3, the effect of time step size on the unsteady pressure results is shown. The number of time steps required for a rotor blade to move by a period was changed from 70 to 140. The corresponding number of time steps per stator blade passing is approximately 133 and 266, respectively. The mean pressure showed no change within plotting accuracy. The variation of the $1^{\text {st }}$ and $2^{\text {nd }}$ harmonic unsteady pressure components along the chord is shown in Fig. 3. The unsteady pressure magnitude is scaled by the inlet total pressure. The nomenclature used is the same as in Ref. [6]: $\mathrm{x} / \mathrm{c}<0$ corresponds to the pressure surface, the leading edge is at $\mathrm{x} / \mathrm{c}=0$, and $\mathrm{x} / \mathrm{c}>0$ corresponds to the suction surface. The $1^{\text {st }}$ harmonic results show very small changes as a result of the doubling of the number of time steps per period. The $2^{\text {nd }}$ harmonic pressure plots show small noticeable differences between the corresponding results. Reducing the time step in half is seen to have only a limited effect on the blade surface pressure distribution, while the required computational effort is doubled. Based on these comparisons, all remaining computations were performed using 70 time steps per rotor period.

The effect of other numerical inputs was also studied. Newton sub-iterations are performed at each time step to drive the residuals below a prescribed limit. The maximum number of such Newton sub-iterations was changed from 3 to 10 . The changes in the unsteady pressure distributions were smaller than those seen in Fig. 3 when the time step was changed. In addition, the number of symmetric Gauss-Seidel passes performed for each sub-iteration was changed from 3 to 6 . The changes in the unsteady pressure distributions were extremely small as compared to those seen in Fig. 3. Due to the extremely limited effect of these changes, the corresponding unsteady pressure distributions are not presented. Based on these comparisons, all remaining computations were performed using 3 Newton sub-iterations and 3 symmetric Gauss-Seidel passes.

\section{Unsteady Flowfields}

The unsteady flowfield for the Run 1 conditions at $85 \%$ span is shown in Fig. 4 in the form of instantaneous Mach number contours at 10 time instants during a passing period. The stator wake is clearly seen sweeping across the rotor blades. The corresponding flowfields at the $50 \%$ span location are similar and are not presented.

Fig. 5 shows a close-up view of the instantaneous flowfields at $85 \%$ and $50 \%$ span. The stator wakes at the $85 \%$ span location oscillate from side to side, and have a wavy appearance. The stator wakes at the $50 \%$ span location are more uniform in appearance and do not show the unsteadiness in location or extent. This spanwise variation in the characteristics of the stator wakes is related to differences in loading. Further work is required to clarify the change in characteristics of the stator wakes along the span. The rotor blades at the $50 \%$ location show distinct vortex shedding. As mentioned earlier, this vortex shedding results in a high frequency variation in the unsteady pressure on the rotor blade surface near the trailing edge (see Fig. $2 \mathrm{c}$ and $2 \mathrm{~d}$ ). In addition, the difference in the pattern of shedding between the $85 \%$ and $50 \%$ span locations results in a difference in the periodicity of the unsteady pressure near the rotor trailing edge (compare Fig. $2 \mathrm{c}$ and $2 \mathrm{~d})$.

\section{Surface Pressure Distributions}

The surface pressure distributions for the Run 1 (small gap) and Run 11 (large gap) conditions at $85 \%$ and $50 \%$ span are shown in Fig. 6 and 7, respectively. The experimental data, including the error in both variables is also shown for comparison. The computational results were obtained using two different grids. For the baseline grid, which was generated 
using established best practices, computations were run on a Cray C90 computer due to the large memory requirements; the results are labeled as "grid2" in Fig. 6 and 7. A coarser grid was used to allow computations to be done on a typical workstation used in industry. The results from this coarser grid are labeled as "grid1" in Fig. 6 and 7.

The results calculated on the two different grids, are seen to be substantially the same. Some differences are noticeable in the phase, but these are typically seen to occur in the regions where the unsteady pressure magnitude is small. The CPU time required to obtain a converged periodic solution starting from an assumed uniform flow was approximately 100 hours on a Cray C90 for the baseline grid. The corresponding CPU time required was nearly twice as much for the coarser grid on a SGI Octane workstation $(300 \mathrm{MHz})$.

The mean surface pressure is seen to agree quite well with the experimental data. In Fig. $6 \mathrm{a}$, the data point near the $\mathrm{x} / \mathrm{c}=$ -0.2 (on the pressure surface) shows a significantly higher mean pressure with a very large error band. The computational results do not show anything unusual in this location. In Fig. $6 \mathrm{~b}$, the data point near the mid-chord on the pressure surface shows a significant drop in pressure, which is also not seen in the computational results. It is not clear if there is a measurement error or if the computations have failed to capture some physical phenomenon.

The magnitude of the $1^{\text {st }}$ harmonic surface pressure agrees quite well with the measured data. The computational results show oscillatory variations along the chord. From the measurements at limited number of points, it is not possible to say whether or not the variations in the computational results are physical. However, results of computations done by the authors using the UNSFLO code (not presented here) show the same oscillatory nature of the $1^{\text {st }}$ harmonic pressure magnitude and phase. Similarly, the computational results presented by Kielb et al. [1] using the UNSFLO code for other conditions show the same oscillatory variations along the chord. The UNSFLO code is a Quasi-3D Reynolds-Averaged NavierStokes code.

In comparing the phase from the TURBO code with data, it is noted that the circumferential position of the rotor with respect to the stator was not recorded in the experiment. Thus, there is an unknown reference in the phase of unsteady pressure measurements, which prevents the comparison of the absolute phase. However, the variations along the chord can still be compared within a constant shift in the phase at all points. The phase from the computational results shows reasonable variations except for the (expected) jumps that occur when the phase changes sign near $\pm 180 \mathrm{deg}$. In addition, it is noted that the phase presented here is for the adjacent blade surfaces of a single passage, rather than for the two surfaces of a single blade.

A comparison of the mean pressure distributions at $85 \%$ span and $50 \%$ span shows that the loading is higher near the tip than at mid-span. This is clearly seen by comparing Fig. 6a and 6b, and Fig. $7 \mathrm{a}$ and $7 \mathrm{~b}$. This difference in loading level is seen in both the data and in the computational results. For the $1^{\text {st }}$ harmonic pressure magnitude, the large peak near the leading edge (suction surface) has a higher magnitude at the $50 \%$ span location as compared to the $85 \%$ span location. Similarly, the other peaks also have a higher magnitude at the $50 \%$ span location. These differences, which result from the spanwise variation in the stator blade loading, are seen for both Run 1 and Run 11; see Fig. 6c and 6d, and Fig. 7c and 7d. The phase at the two span locations is substantially similar in trends for Run 1 (Fig. 6e and 6f) with some differences in the values at corresponding chordwise locations, and the chordwise locations of some features in the variations. For Run 11 (Fig. 7e and 7f), additional differences are seen in the phase. For example, the variation seen in phase between $\mathrm{x} / \mathrm{c}=0.0$ and 0.2 in Fig. 7e has no counterpart in Fig. 7f.

A comparison of the $1^{\text {st }}$ harmonic pressure for Run 1 (small gap) and Run 11 (large gap) shows the effect of changing the axial gap. Comparing Fig. $6 \mathrm{c}$ with $7 \mathrm{c}$, or Fig. $6 \mathrm{~d}$ with $7 \mathrm{~d}$ shows that increasing the axial gap leads to a reduction in the magnitude of the main pressure peak near the leading edge. On the other hand, some of the smaller peaks are seen to increase in magnitude and the number of the smaller peaks is seen to change. The suction surface distributions in Fig. $6 \mathrm{~d}$ and $7 \mathrm{~d}$ illustrate these observations. The effect of such changes in the pressure distributions on the overall response is of particular interest.

The results presented thus far have been restricted to the Run 1 and 11 conditions. It is neither possible nor useful to present all the results for the other conditions listed in Table 1 for which computations have been done. Results are presented in Fig. 8 showing the mean and $1^{\text {st }}$ harmonic magnitude of pressure at $50 \%$ span for Run 4 and 7 . These results show the effect of the change in rotational speed (19500 rpm to 10100 $\mathrm{rpm}$ ), pressure ratio (2.1 to 1.6), and inlet conditions. Also, these results show the same good agreement with experimental data as seen in previous results. The mean pressure level is seen to be higher for the Run 7 conditions and the effect of the increased incidence is clear. The $1^{\text {st }}$ harmonic pressure magnitude is seen to have significantly smaller leading edge peak for the Run 7 conditions. In addition, the range of variation in pressure for the remaining peaks is smaller for Run 7.

\section{CONCLUDING REMARKS}

Computations have been performed for a high pressure turbine using the TURBO code. The unsteady flowfield for two configurations and six conditions has been computed. The accuracy of the computational results has been checked by varying the relevant numerical parameters. The choice of various numerical parameters and inputs is shown to have a very limited effect on the results. Results obtained from computations on two grids have shown no significant differences in unsteady surface pressure. 
The computational results have agreed quite well with the experimental data at both spanwise locations and at different run conditions. The mean loading near the tip is seen to be higher than at the mid-span location. The trend is reversed for the unsteady loading, with the higher unsteady loads occurring at the mid-span. A comparison of the surface pressure for Run 1 (small gap) and Run 11 (large gap) conditions has shown that the main pressure peak near the leading edge is smaller for the larger axial gap. The effect of change in the rotational speed and pressure ratio has been shown through a comparison of the surface pressure for the Run 4 and 7 conditions. The effect of the increased incidence (Run 7) is clearly seen in the mean pressure distribution. The $1^{\text {st }}$ harmonic magnitude of unsteady pressure shows a reduction for Run 4 conditions, along with a decreased range of oscillations in the values. These effects are directly related to the decreased rotational speed.

Additional work is required to correlate the features in the pressure distribution to physical phenomena occurring in the flowfield; a space-time plot may be used as a first step in this effort. Such work will allow for an understanding of the oscillatory chordwise distribution seen in the computational results. Future work is also expected to include a comparison between the computed and measured blade vibratory strains. Additional information regarding the experimental data is required before such a direct comparison can be made. In addition, future work is expected to include a direct comparison of the present computational results with results from other CFD codes such as UNSFLO. Such comparison between computational results is necessary to verify the results since the measurements are available at a small number of pressure sensor locations. Further, such a comparison may help identify physical phenomena that are captured well by one CFD code, or the other, or neither.

\section{REFERENCES}

[1] Kielb, J. J., Abhari, R. S., and Dunn, M. G., "Experimental and Numerical Study of Forced Response in a Full-Scale Rotating Turbine," ASME Paper 2001GT-0263, 2001.

[2] Chen, J. P., and Whitfield, D. L., "Navier-Stokes Calculations for the Unsteady Flowfield of Turbomachinery," AIAA Paper 93-0676, 1993.

[3] Chen, J. P., Celestina, M., and Adamczyk, J. J., “A New Procedure for Simulating Unsteady Flows through Turbomachinery Blade Passages," ASME Paper 94-GT151, 1994.

[4] Chen, J. P., and Barter, J. W., "Comparison of TimeAccurate Calculations for the Unsteady Interaction in Turbomachinery Stage,” AIAA Paper 98-3292, 1998.

[5] Kielb, J. J., and Abhari, R. S., "Experimental Study of Aerodynamic and Structural Damping in a Full-Scale Rotating Turbine," ASME Paper 2001-GT-0262, 2001.

[6] Kielb, J. J., "Experimental and Numerical Study of Blade Forced Response in a Full-Scale Rotating Turbine," M.S. thesis, Department of Aeronautical and Astronautical Engineering, Ohio State University, 2000.

[7] Janus, J. M., "Advanced 3-D CFD Algorithm for Turbomachinery", Ph.D. Dissertation, Mississippi State University, Mississippi, 1989.

[8] Chen, J. P., "Unsteady Three-Dimensional Thin-Layer Navier-Stokes Solutions for Turbomachinery in Transonic Flow", Ph.D. Dissertation, Mississippi State University, Mississippi, 1991.

[9] Erdos, J. I., Alzner, E., and McNally, W., "Numerical Solution of Periodic Transonic Flow Through a Fan Stage", AIAA Journal, Vol. 15, pp. 1559-1568, 1977.

Table 1: Summary of conditions used in TURBO calculations

\begin{tabular}{|c|c|c|c|c|c|c|}
\hline Run & Mode & $\begin{array}{c}\text { Rotational } \\
\text { Speed } \\
(\text { RPM) }\end{array}$ & $\begin{array}{c}\text { Inlet } \\
\text { Pressure } \\
(\mathbf{P a})\end{array}$ & $\begin{array}{c}\text { Inlet } \\
\text { Temper- } \\
\text { ature (K) }\end{array}$ & $\begin{array}{c}\text { Pressure } \\
\text { Ratio }\end{array}$ & $\begin{array}{c}\text { Axial } \\
\text { Spacing }\end{array}$ \\
\hline 1 & $3($ axial $)$ & 15000 & 289590 & 296 & 2.1 & $32 \%$ \\
\hline 11 & $3($ axial$)$ & 15000 & 289590 & 296 & 2.0 & $46 \%$ \\
\hline 4 & $4\left(2^{\text {nd }}\right.$ bending) & 19500 & 558495 & 553 & 2.1 & $32 \%$ \\
\hline 16 & $4\left(2^{\text {nd }}\right.$ bending $)$ & 19500 & 565390 & 553 & 2.1 & $46 \%$ \\
\hline 7 & $2\left(1^{\text {st }}\right.$ torsion $)$ & 10100 & 289590 & 296 & 1.6 & $32 \%$ \\
\hline 14 & $2\left(1^{\text {st }}\right.$ torsion $)$ & 10100 & 289590 & 296 & 1.6 & $46 \%$ \\
\hline
\end{tabular}




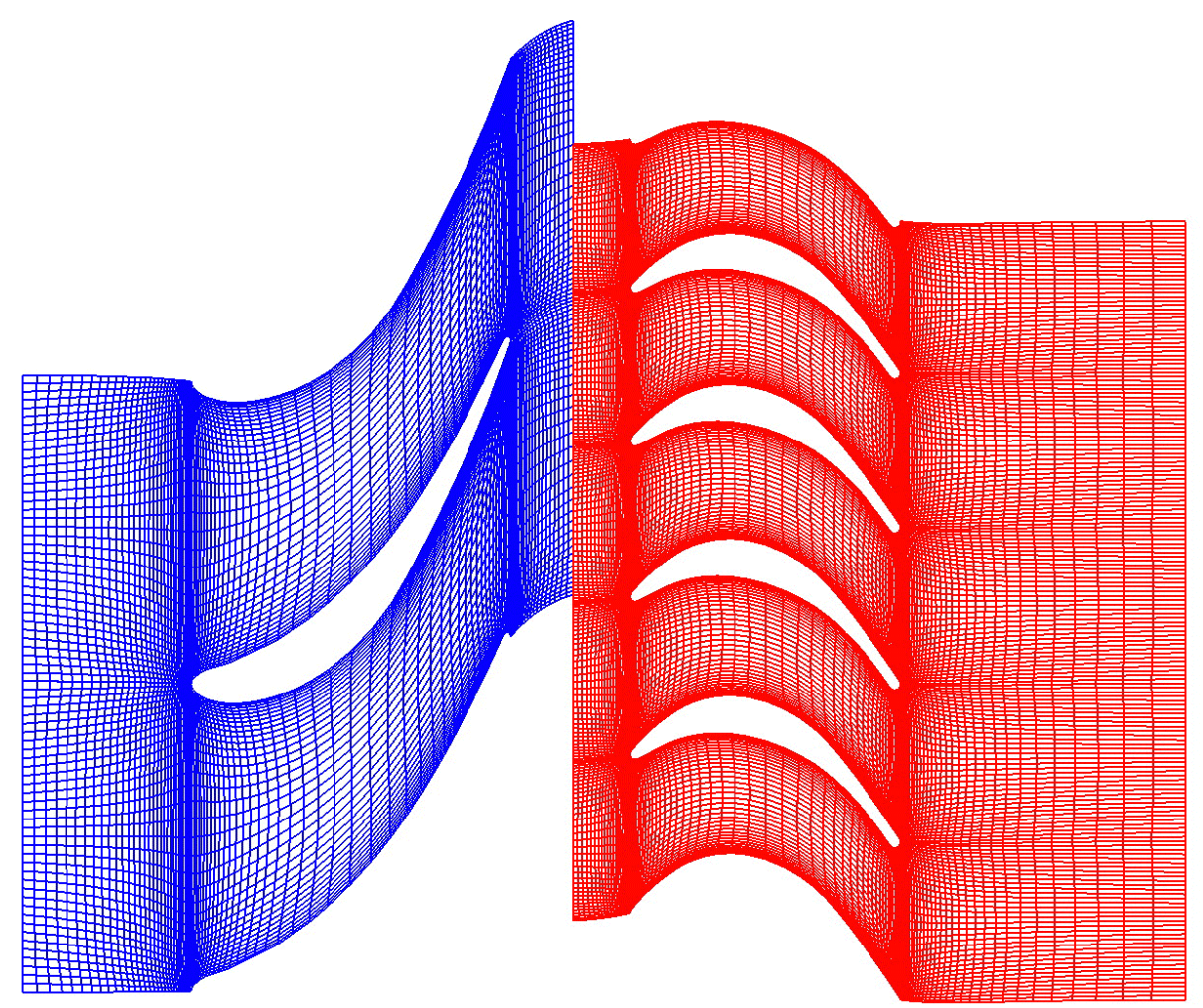

Figure 1a: Smoothed H-grids used in TURBO calculations

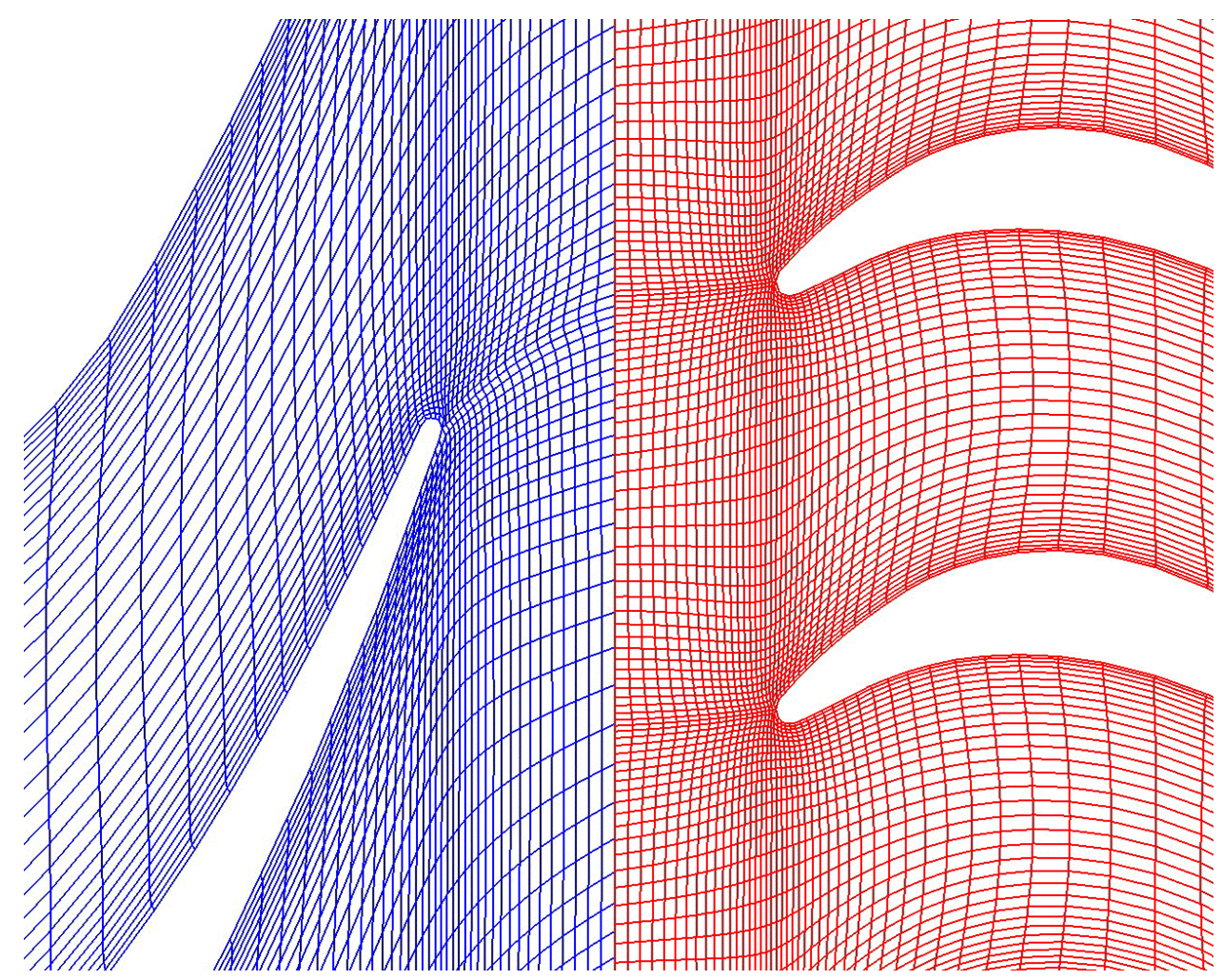

Figure 1b: Close-up view of grid showing details near trailing and leading edges 


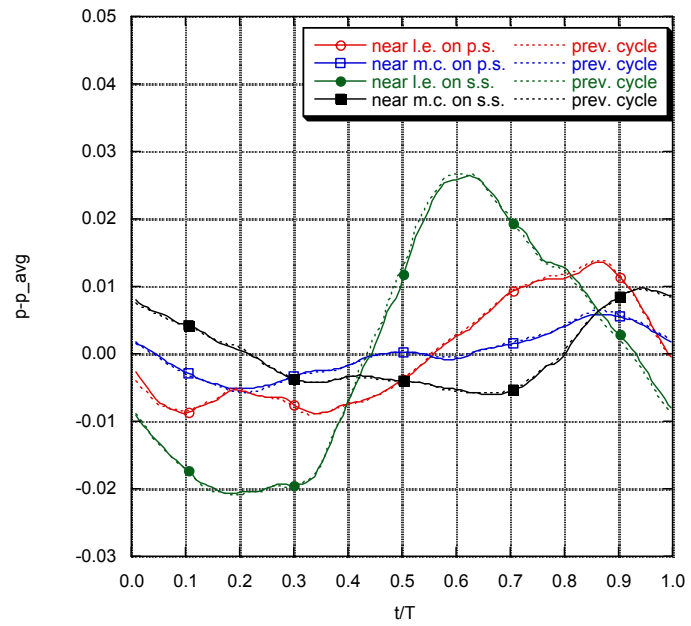

(a) $85 \%$ span, near leading edge and mid-chord

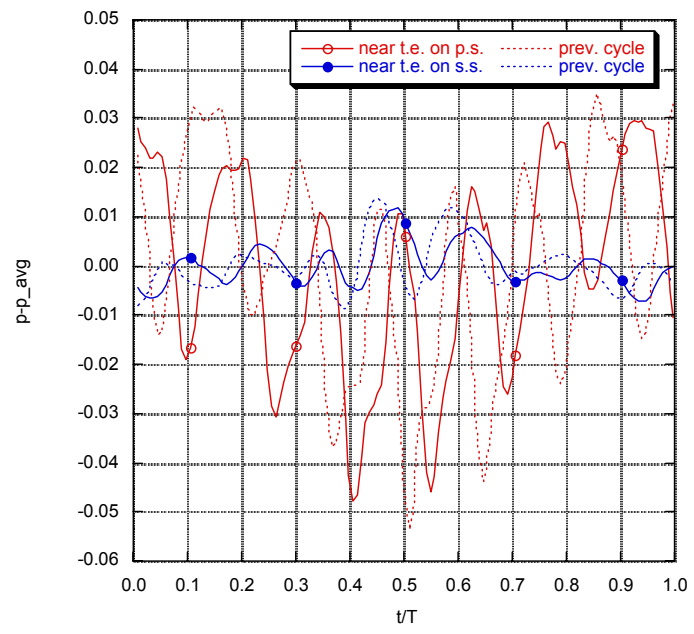

(c) $85 \%$ span, near trailing edge

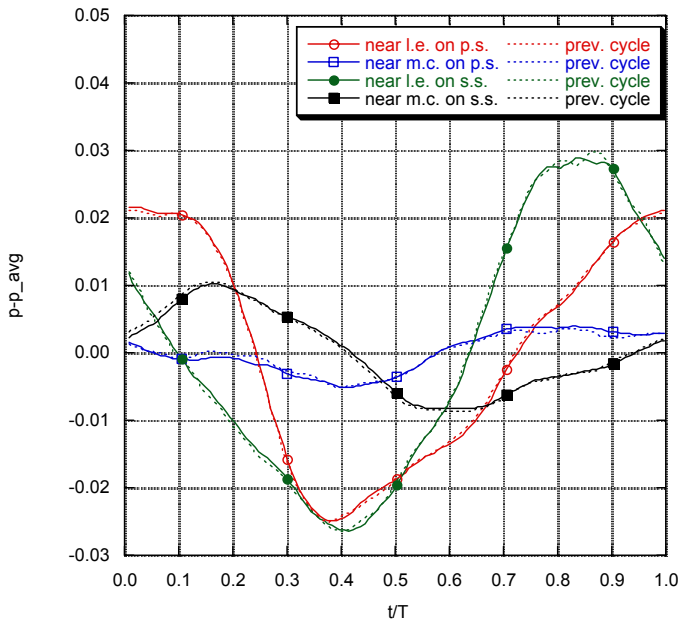

(b) $50 \%$ span, near leading edge and mid-chord

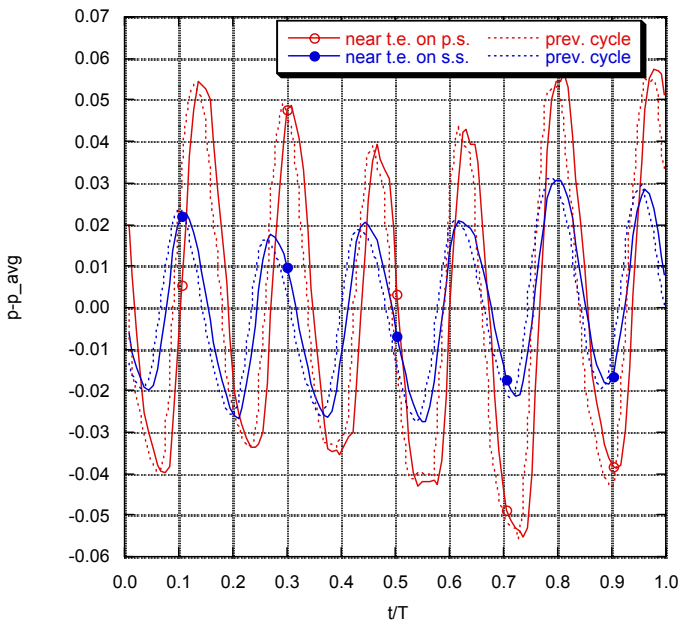

(d) $50 \%$ span, near trailing edge

Figure 2: Periodicity of unsteady blade surface pressure, Run 1 conditions 


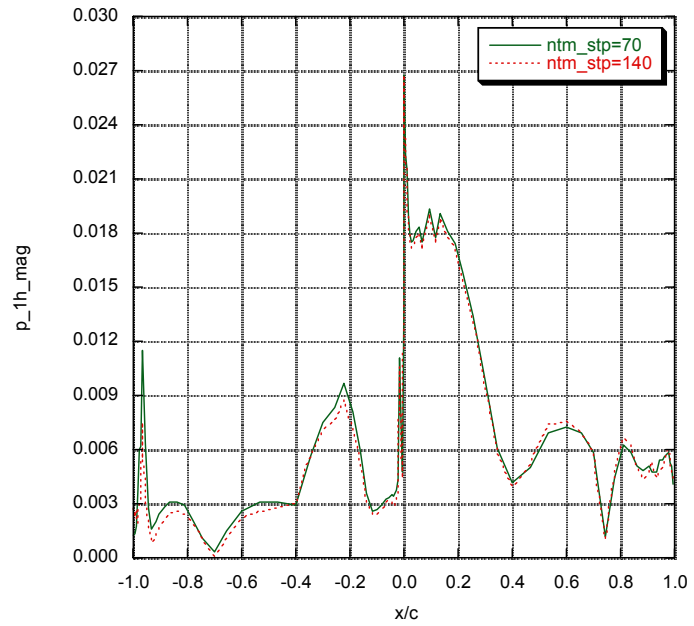

(a) $85 \%$ span, $1^{\text {st }}$ harmonic magnitude

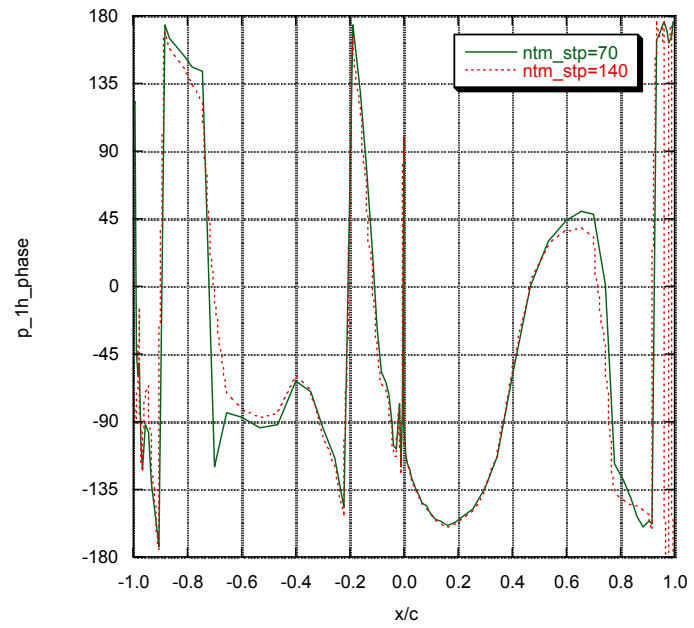

(c) $85 \%$ span, $1^{\text {st }}$ harmonic phase

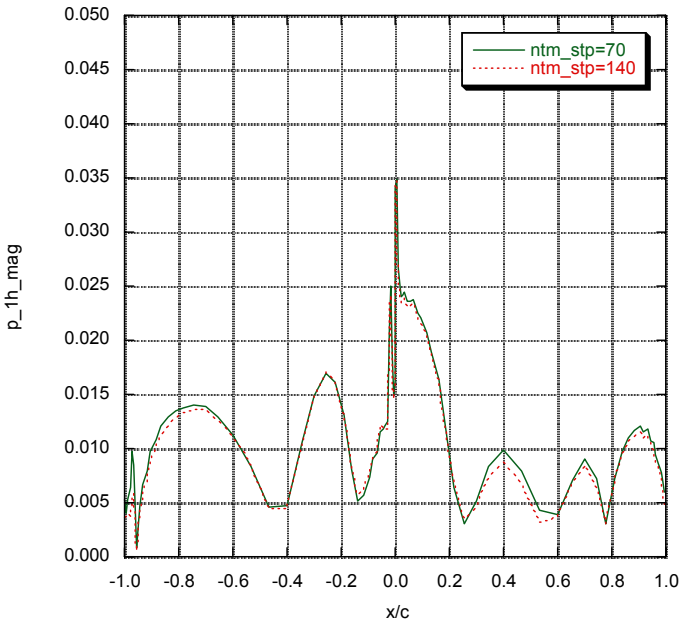

(b) $50 \%$ span, $1^{\text {st }}$ harmonic magnitude

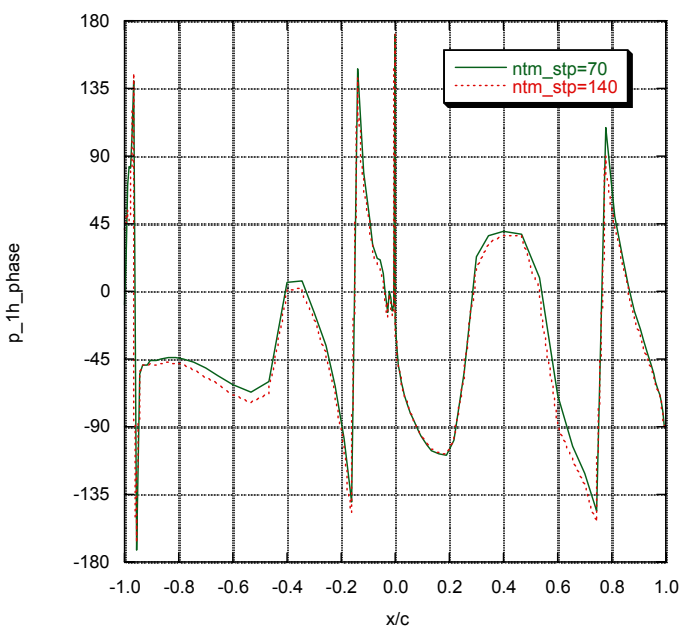

(d) $50 \%$ span, $1^{\text {st }}$ harmonic phase

Figure 3: Effect of number of time steps per period, Run 1 conditions 


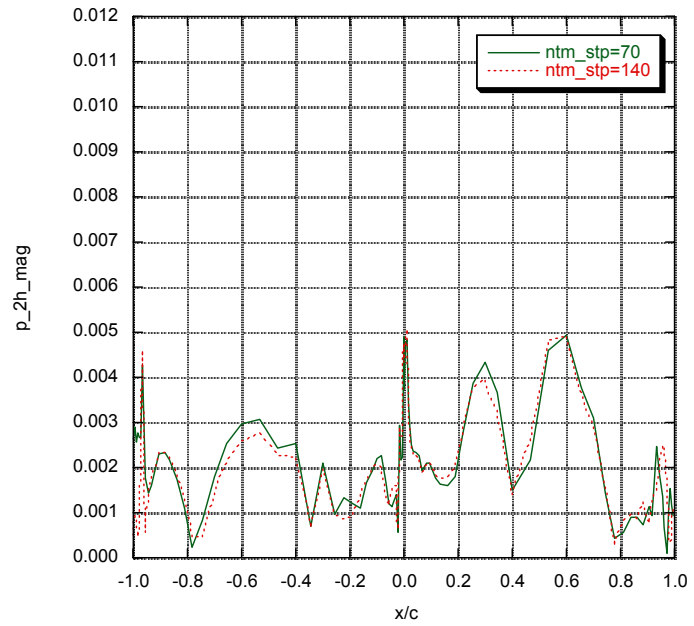

(e) $85 \%$ span, $2^{\text {nd }}$ harmonic magnitude

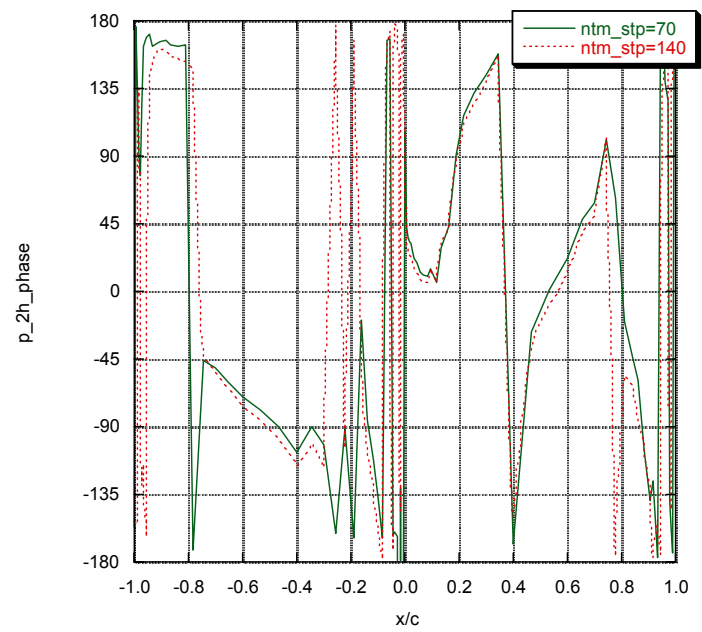

(g) $85 \%$ span, $2^{\text {nd }}$ harmonic phase

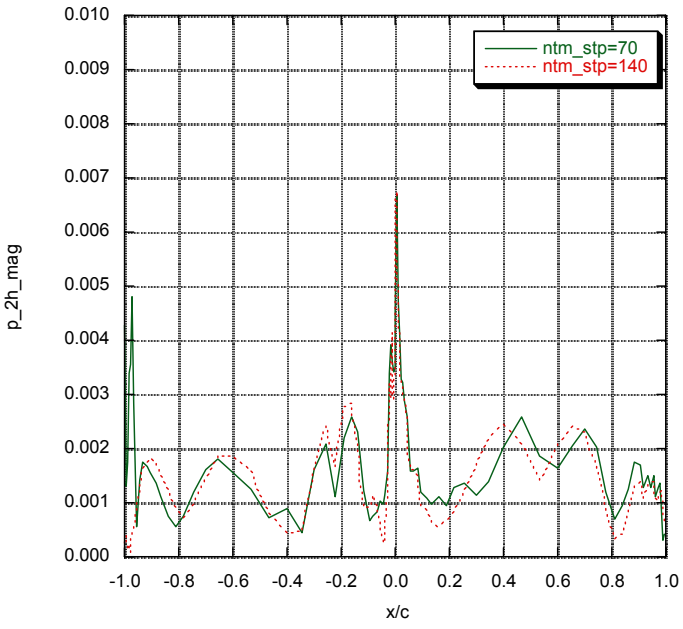

(f) $50 \%$ span, $2^{\text {nd }}$ harmonic magnitude

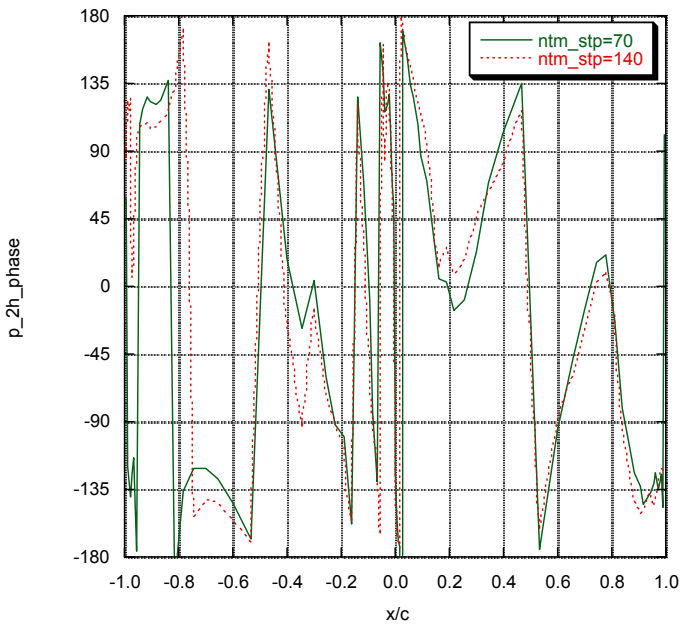

(h) $50 \%$ span, $2^{\text {nd }}$ harmonic phase

Figure 3 (continued): Effect of number of time steps per period, Run 1 conditions 

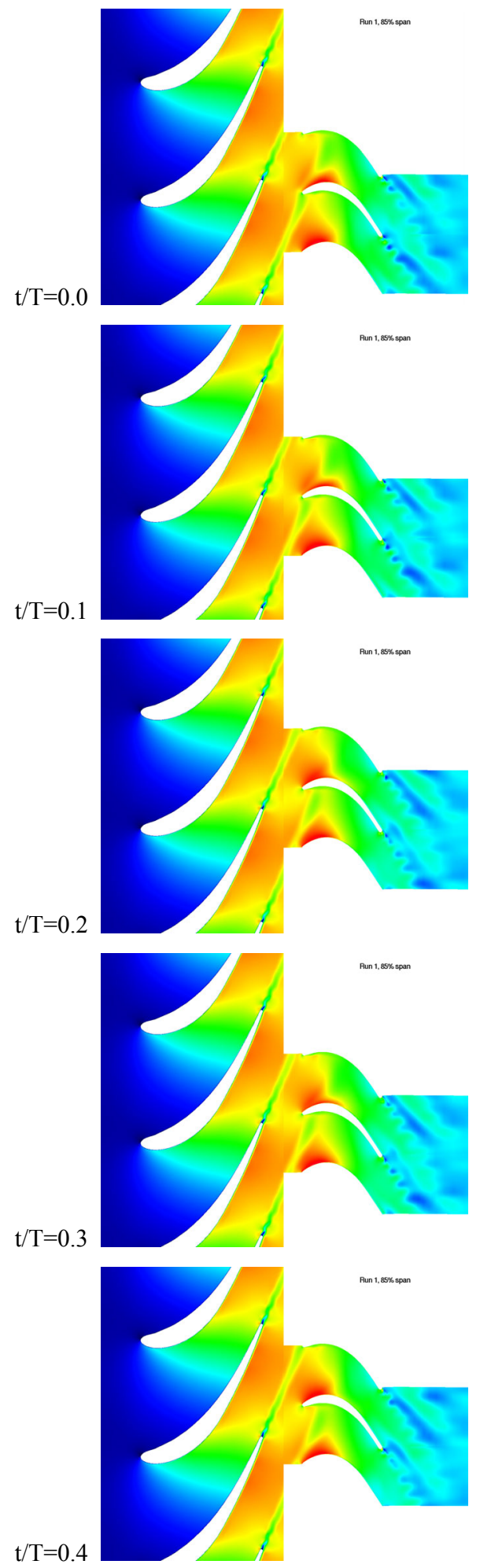
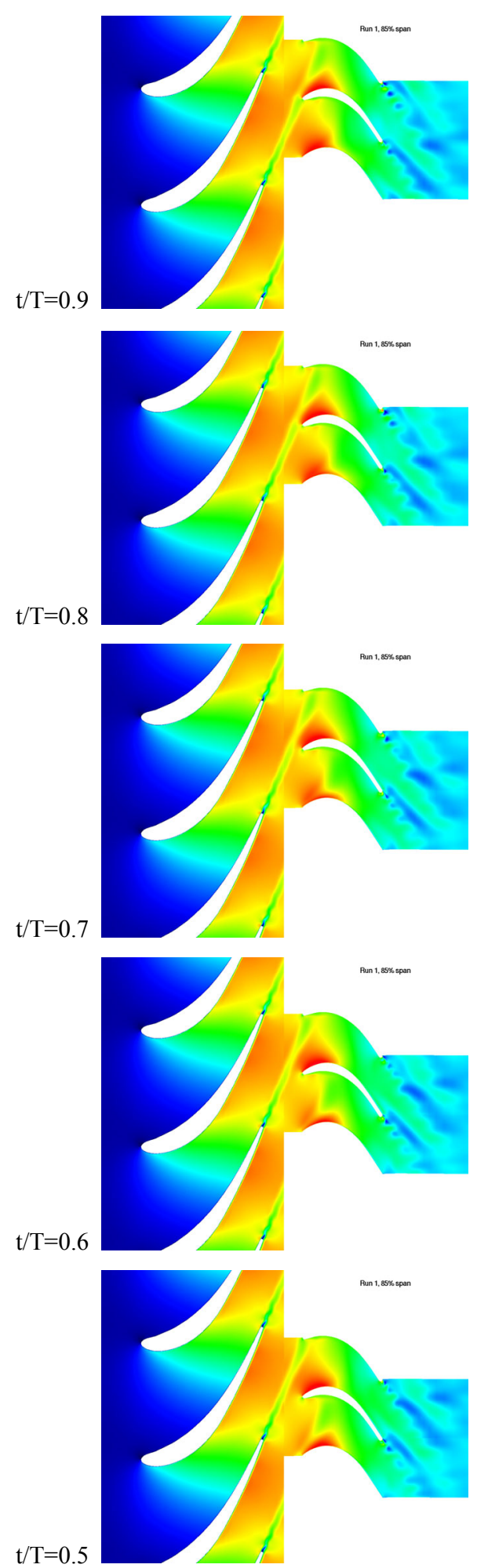

Figure 4: Instantaneous Mach number contours at the $85 \%$ spanwise location, Run 1 conditions 

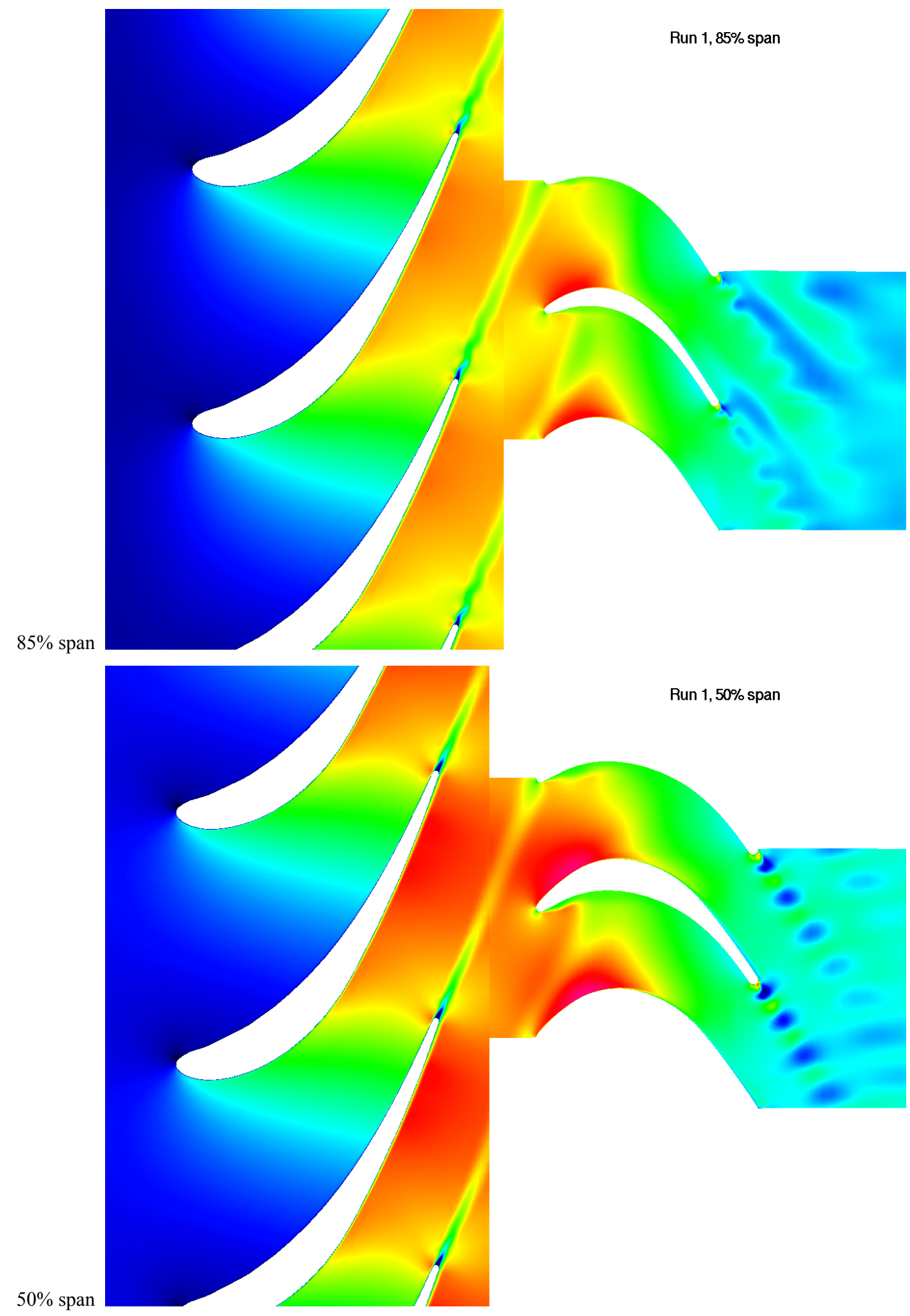

Figure 5: Comparison of the flowfield upstream of the rotor at the $85 \%$ and $50 \%$ span, Run 1 conditions 


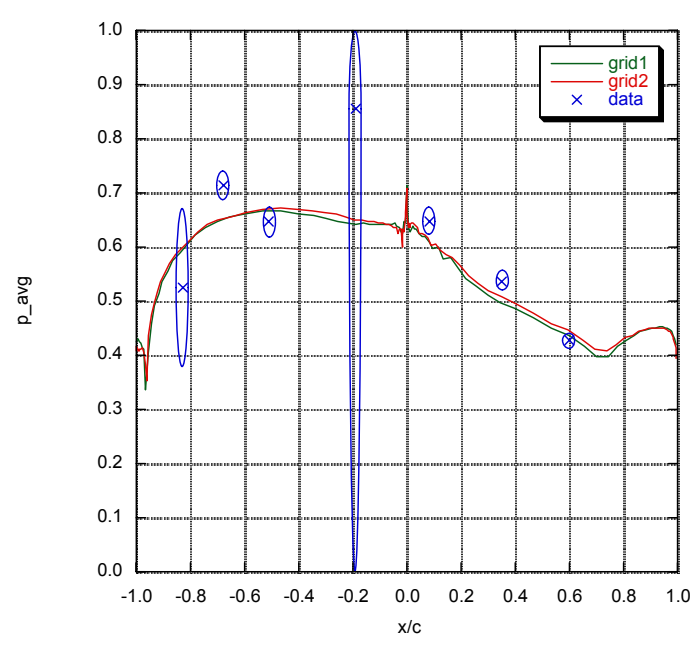

(a) $85 \%$ span, mean

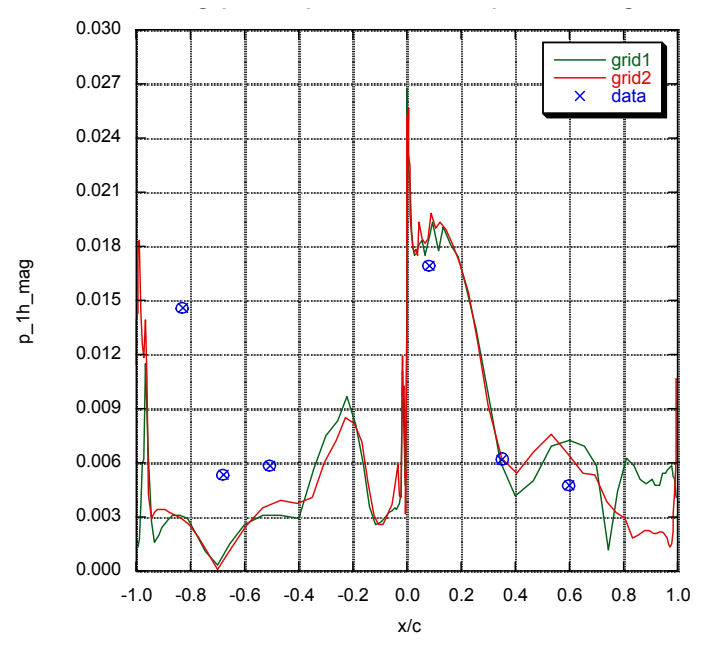

(c) $85 \%$ span, $1^{\text {st }}$ harmonic magnitude

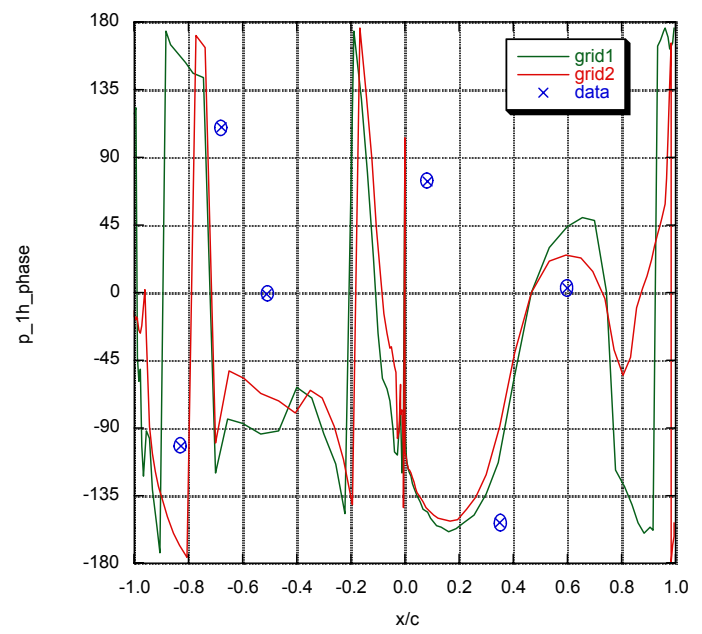

(e) $85 \%$ span, $1^{\text {st }}$ harmonic phase

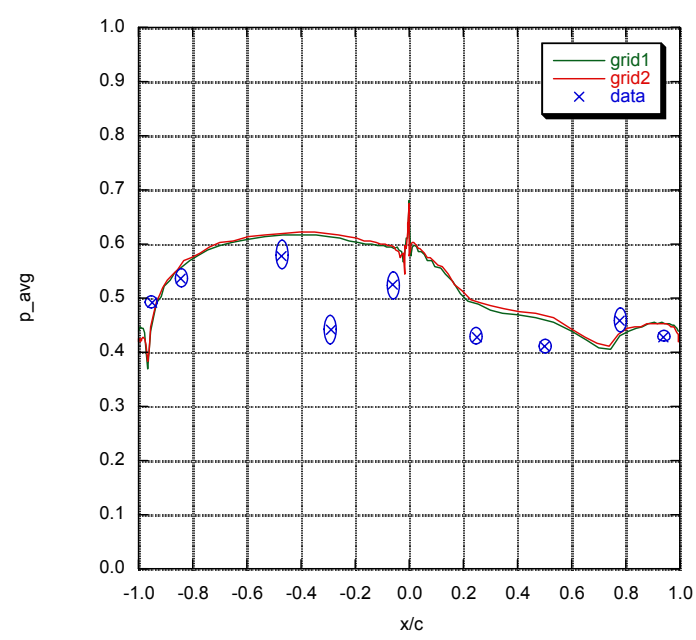

(b) $50 \%$ span, mean

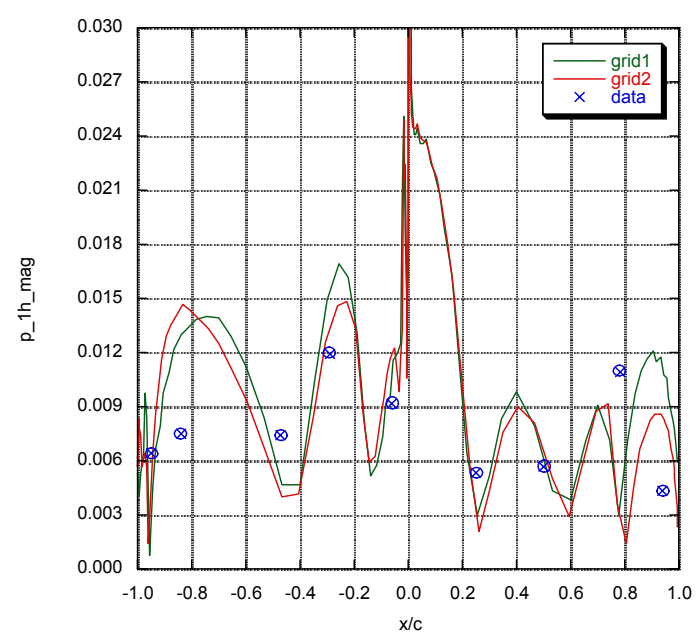

(d) $50 \%$ span, $1^{\text {st }}$ harmonic magnitude

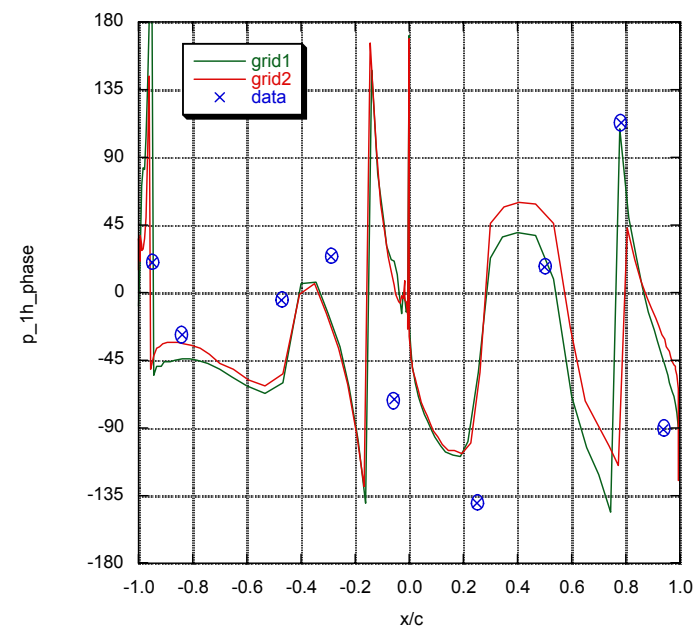

(f) $50 \%$ span, $1^{\text {st }}$ harmonic phase

Figure 6: Surface pressure distributions for Run 1 conditions 


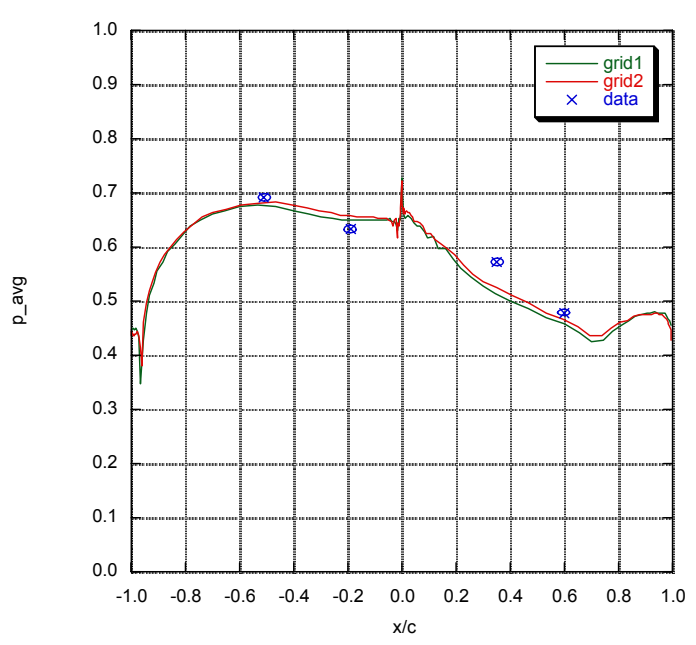

(a) $85 \%$ span, mean

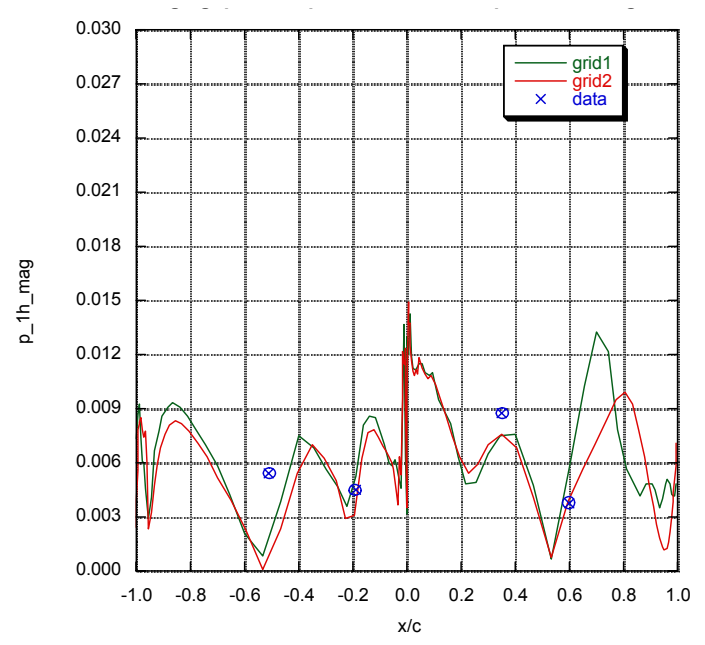

(c) $85 \%$ span, $1^{\text {st }}$ harmonic magnitude

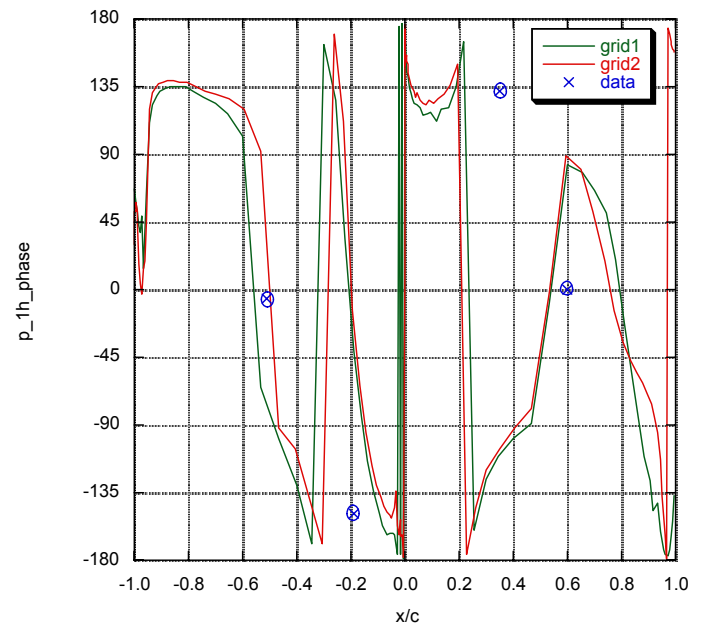

(e) $85 \%$ span, $1^{\text {st }}$ harmonic phase

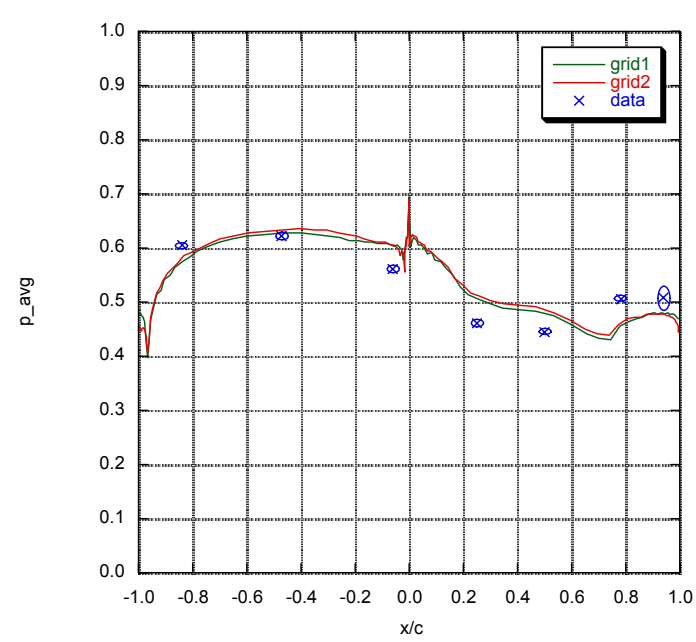

(b) $50 \%$ span, mean

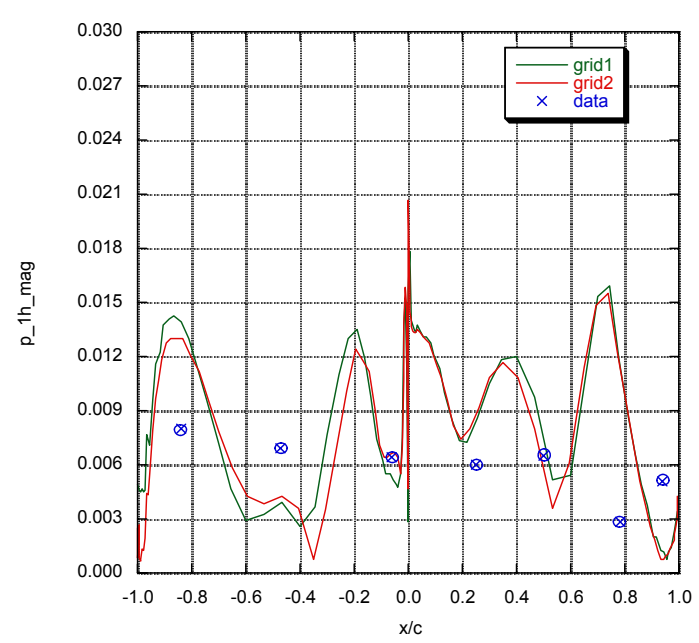

(d) $50 \%$ span, $1^{\text {st }}$ harmonic magnitude

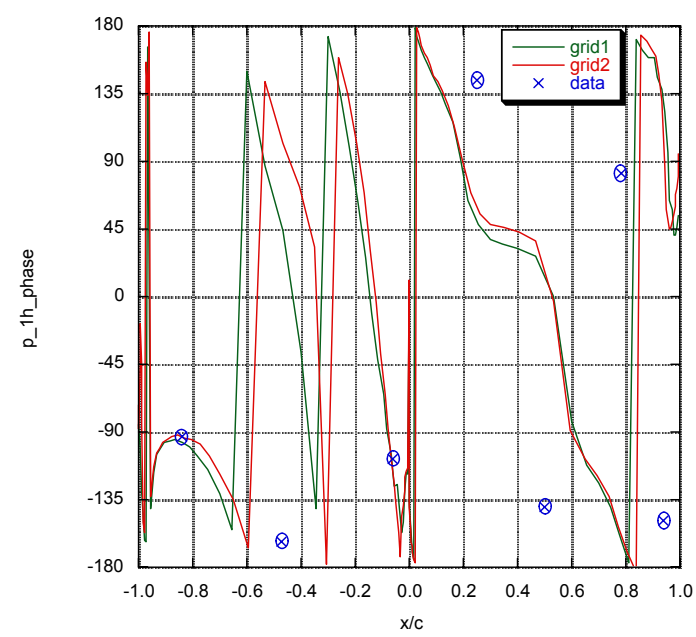

(f) $50 \%$ span, $1^{\text {st }}$ harmonic phase

Figure 7: Surface pressure distributions for Run 11 conditions 


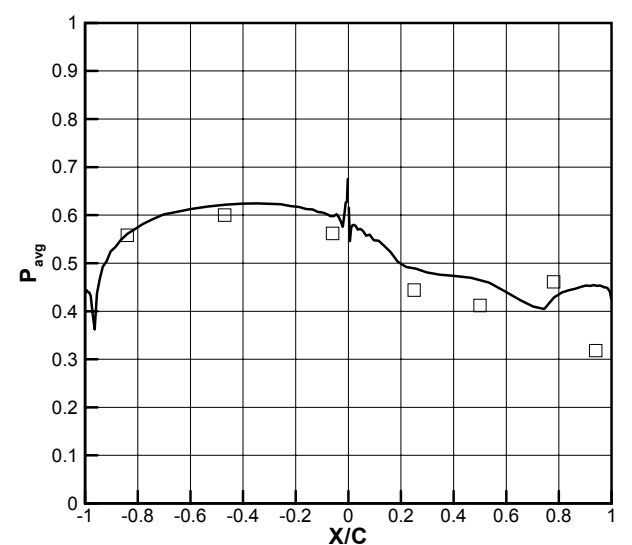

(a) Run 4 conditions, mean

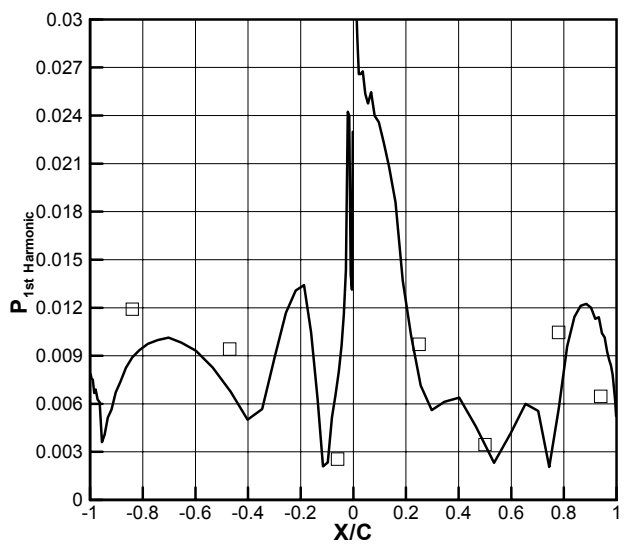

(c) Run 4 conditions, $1^{\text {st }}$ harmonic magnitude

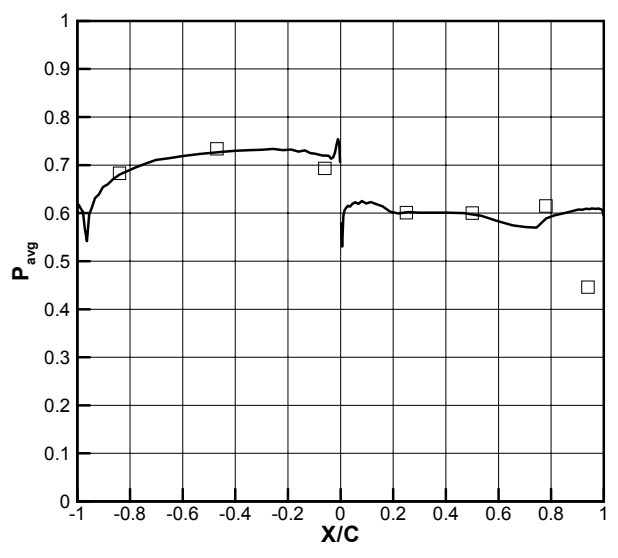

(b) Run 7 conditions, mean

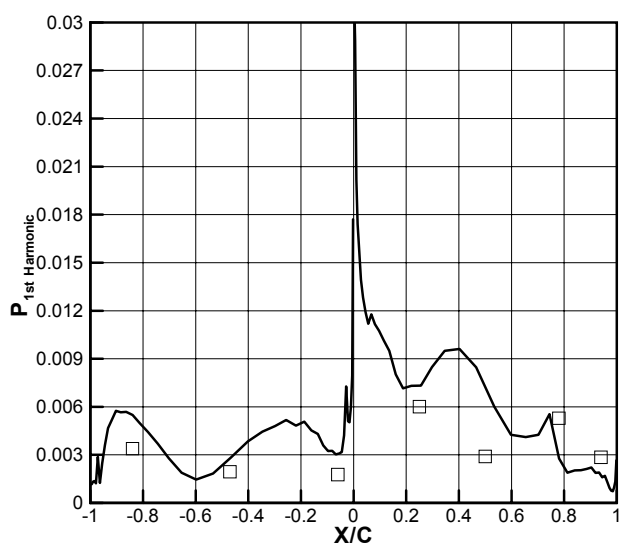

(d) Run 7 conditions, $1^{\text {st }}$ harmonic magnitude

Figure 8: Surface pressure distributions for Run 4 and 7 conditions at $50 \%$ span 


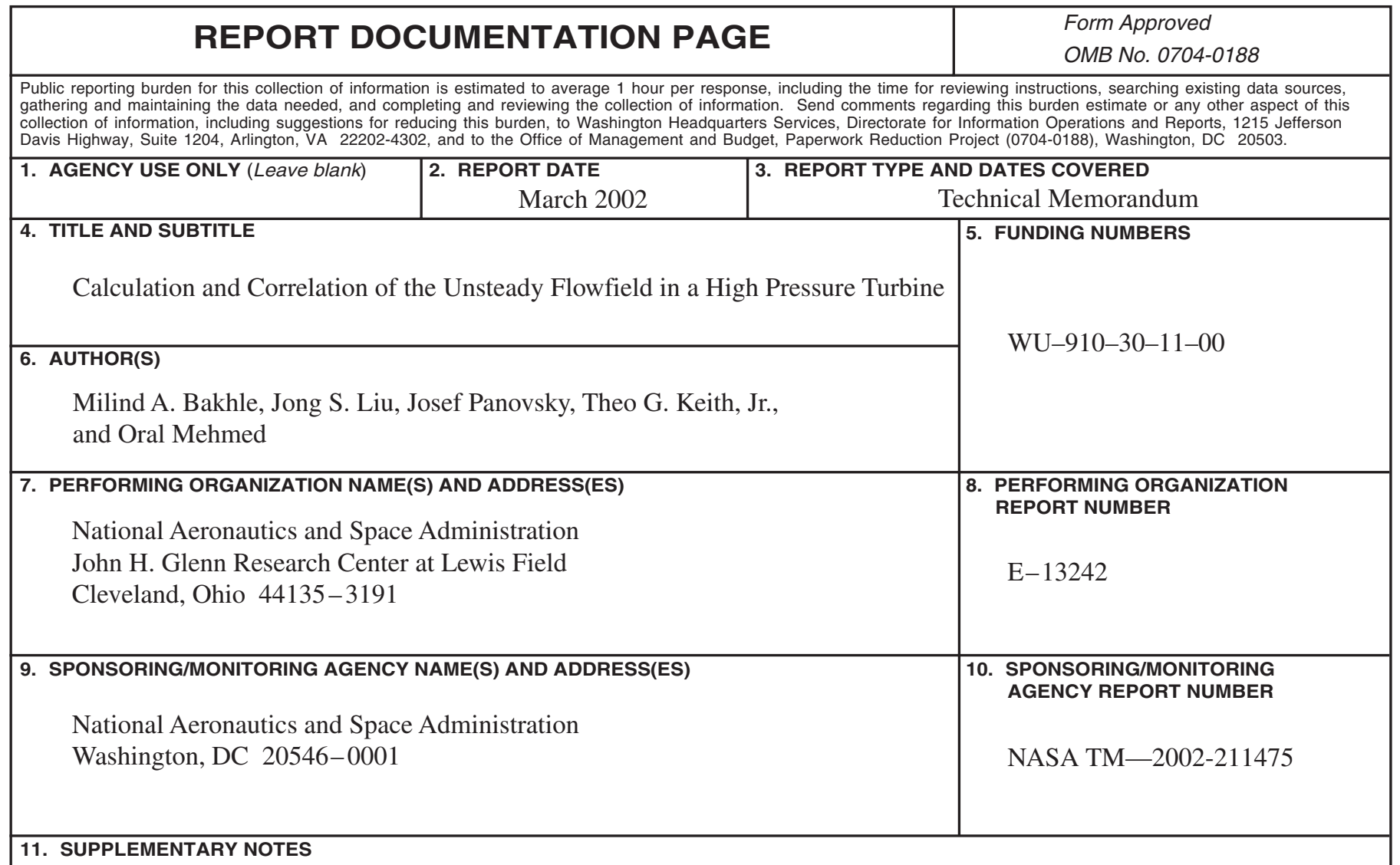

Prepared for the Turbo Expo 2002 sponsored by the American Society of Mechanical Engineers and the International Gas Turbine Institute, Amsterdam, The Netherlands, June 3-6, 2002. Milind A. Bakhle and Theo G. Keith, Jr., University of Toledo, Toledo, Ohio; Jong S. Liu and Josef Panovsky, Honeywell Engines, Systems, \& Services, Pheonix, Arizona; Oral Mehmed, NASA Glenn Research Center. Responsible person, Milind A. Bakhle, organization code 5930, $216-433-6037$.

\begin{tabular}{|l|l}
\hline 12a. DISTRIBUTION/AVAILABILITY STATEMENT & 12b. DISTRIBUTION CODE
\end{tabular}

Unclassified - Unlimited

Subject Categories: 02 and 07

Distribution: Nonstandard

Available electronically at http://gltrs.grc.nasa.gov/GLTRS

This publication is available from the NASA Center for AeroSpace Information, 301-621-0390.

13. ABSTRACT (Maximum 200 words)

Forced vibrations in turbomachinery components can cause blades to crack or fail due to high-cycle fatigue. Such forced response problems will become more pronounced in newer engines with higher pressure ratios and smaller axial gap between blade rows. An accurate numerical prediction of the unsteady aerodynamics phenomena that cause resonant forced vibrations is increasingly important to designers. Validation of the computational fluid dynamics (CFD) codes used to model the unsteady aerodynamic excitations is necessary before these codes can be used with confidence. Recently published benchmark data, including unsteady pressures and vibratory strains, for a high-pressure turbine stage makes such code validation possible. In the present work, a three dimensional, unsteady, multi blade-row, Reynolds-Averaged Navier Stokes code is applied to a turbine stage that was recently tested in a short duration test facility. Two configurations with three operating conditions corresponding to modes 2, 3, and 4 crossings on the Campbell diagram are analyzed. Unsteady pressures on the rotor surface are compared with data.

14. SUBJECT TERMS

\begin{tabular}{|c|c|}
\hline & $\begin{array}{c}\text { 15. NUMBER OF PAGES } \\
20 \\
\end{array}$ \\
\hline & 16. PRICE CODE \\
\hline $\begin{array}{l}\text { 9. SECURITY CLASSIFICATION } \\
\text { OF ABSTRACT }\end{array}$ & 20. LIMITATION OF ABSTRACT \\
\hline Unclassified & \\
\hline
\end{tabular}

Forced response; Turbine; Navier-Stokes; Unsteady flow

\begin{tabular}{|c|c|}
\hline $\begin{array}{c}\text { 17. SECURITY CLASSIFICATION } \\
\text { OF REPORT } \\
\text { Unclassified }\end{array}$ & $\begin{array}{c}\text { 18. SECURITY CLASSIFICATION } \\
\text { OF THIS PAGE } \\
\text { Unclassified }\end{array}$ \\
\hline
\end{tabular}

NSN 7540-01-280-5500

Standard Form 298 (Rev. 2-89)

Prescribed by ANSI Std. Z39-18 298-102 